\title{
Silver(I) and zinc(II) complexes with symmetrical cinnamaldehyde Schiff base derivative: Spectroscopic, powder diffraction characterization, and antimycobacterial studies
}

\author{
Thaeny C. Amaral a , Fábio B. Miguel ${ }^{\mathrm{b}}$, Mara R.C. Couri ${ }^{\mathrm{b}}$, Pedro P. Corbi ${ }^{\mathrm{c}}$, Marcos A. Carvalho ${ }^{\mathrm{c}}$, \\ Débora L. Campos ${ }^{\mathrm{d}}$, Fernando R. Pavan ${ }^{\mathrm{d}}$, Alexandre Cuin ${ }^{\mathrm{a}, *}$ \\ ${ }^{a}$ LQBin, Laboratório de Química BioInorgânica, Departamento de Química, Instituto de Ciências Exatas, UFJF, 36036-330 Juiz de Fora, MG, Brazil \\ ${ }^{\mathrm{b}}$ Departamento de Química, Instituto de Ciências Exatas, UFJF, 36036-330 Juiz de Fora, MG, Brazil \\ ' Instituto de Química, Universidade Estadual de Campinas, UNICAMP, 13083-970, Campinas, SP, Brazil \\ ${ }^{\mathrm{d}}$ Laboratório de Pesquisas em Tuberculose, Departamento de Ciências Biológicas, Faculdade de Ciências Farmacêuticas, UNESP, 14801-903 Araraquara, SP, Brazil
}

\section{A R T I C L E I N F O}

\section{Article history:}

Received 8 August 2017

Accepted 28 February 2018

Available online 15 March 2018

\section{Keywords:}

Cinnamaldehyde

Schiff bases

Metal ions

Tuberculosis

Powder diffraction

\begin{abstract}
A B S T R A C T
Silver(I) and zinc(II) complexes with $N, N^{\prime}$-bis(trans-cinnamaldehyde)ethane-1,2-diamine (EnCinn) have been synthesized and characterized by elemental analysis, simultaneous thermogravimetric and differential thermal studies (TG-DTA), infrared (IR), ${ }^{1} \mathrm{H}$ and ${ }^{13} \mathrm{C}$ nuclear magnetic resonance (NMR) spectroscopic measurements and electrospray ionization quadrupole time-of-flight mass spectrometry (ESI-QTOF-MS). Crystal and molecular structure descriptions were performed based on powder X-ray diffraction data. The AgEnCinn complex has a polymeric structure where the ligand bridges between two $\mathrm{Ag}(\mathrm{I})$ ions, while the ZnEnCinn complex has a monomeric structure with EnCinn acting as chelating ligand. Antimycobacterial assays over Mycobacterium tuberculosis showed the activity of the $\mathrm{Ag}(\mathrm{I}) \mathrm{com}-$ plex with Minimum Inhibitory Concentration (MIC) value of $22.7 \mu \mathrm{mol} \mathrm{L}^{-1}$, while the $\mathrm{Zn}$ (II) complex was shown to be inactive over the same experimental conditions.
\end{abstract}

(c) 2018 Elsevier Ltd. All rights reserved.

\section{Introduction}

Tuberculosis (TB) is an endemic disease that affect millions of people in many countries. TB is a common infection in populations living in poverty conditions, without adequate sanitation and in close contact with infectious vectors. In 2016, more than 6.3 million new cases of TB were reported, while in 2015 the number of cases informed was of 6.1 million. Besides the number of infected people increases year after year, drug-resistant TB is also a continuing threat. In 2016, there were nearly 600.000 new cases with resistance to rifampicin (RRTB), the most effective first-line drug [1]. Therefore, much effort has been expended to find new classes of compounds able to defeat the Mycobacterium tuberculosis - the mycobacterium that causes tuberculosis.

In this sense, many research groups around the world have addressed their research on metal complexes with therapeutic activities over $M$. tuberculosis, especially silver(I) complexes, since some compounds of this class have demonstrated high anti-TB activity. In our recent papers, silver(I) complexes with alfa-hydroxy

\footnotetext{
* Corresponding author.

E-mail address: alexandre.cuin@ufjf.edu.br (A. Cuin).
}

acids [2], amino acids [3], benzothiazoles [4], mercaptopurines [5] and Schiff bases [6,7] synthesized in our laboratories, have shown to be more effective against $M$. tuberculosis than silver sulfadiazine (SSD), a standard and widely commercial silver(I) complex used in the treatment of bacterial infections in burns and skin wounds. Besides biological properties of $\mathrm{Ag}(\mathrm{I})$ ions, $\mathrm{Zn}$ (II) ions are essential factors for many biological processes and their complexes are present in a broad spectrum of biological functions [8]. Indeed, our group has been looking for ligands from natural sources and with biological properties. In this way, $\mathrm{Ag}(\mathrm{I})$ and $\mathrm{Zn}(\mathrm{II})$ ions were combined with a $\mathrm{N}$-donor ligand from cinnamaldehyde (CA), a major constituent of cinnamon essential oil, extracted from bark of cinnamon trees of the Cinnamomum genus. CA is also a natural antimicrobial substance that is generally recognized as safe (GRAS) by the U.S. Food and Drug Administration. Since cinnamaldehyde has conjugated double bonds with $\mathrm{C}=\mathrm{O}$ group, it forms stable Schiff bases with amine compounds $\left(-\mathrm{NH}_{2}\right)$ [9].

In this paper we report the synthesis of new $\mathrm{Ag}(\mathrm{I})$ and $\mathrm{Zn}(\mathrm{II})$ complexes with the symmetrical Schiff base $N, N^{\prime}$-bis(trans-cinnamaldehyde)ethane-1,2-diamine (EnCinn) and their structural characterizations based on spectroscopic and on powder X-ray 
diffraction data. Biological studies of the complexes over M. tuberculosis are also reported.

\section{Experimental}

\subsection{Materials and methods}

Ethylenediamine (99\%), trans-cinnamaldehyde (99\%), silver nitrate (99\%) and anhydrous zinc chloride (98\%) were purchased from Sigma-Aldrich Laboratories. Elemental analyses of carbon, hydrogen and nitrogen were performed using a CHNS/O Perkin Elmer 2400 Analyzer. Infrared spectra were measured using a Spectrum 2000 FT-IR Perkin Elmer spectrophotometer in the range $4000-400 \mathrm{~cm}^{-1}$ with resolution of $4 \mathrm{~cm}^{-1}$; samples were prepared as $\mathrm{KBr}$ pellets.

The ${ }^{1} \mathrm{H}$ and ${ }^{13} \mathrm{C}$ NMR spectra of EnCinn were recorded on a Bruker Avance $500 \mathrm{MHz}$ spectrophotometer, operating at $499.9 \mathrm{MHz}$ for ${ }^{1} \mathrm{H}$ and at $125.7 \mathrm{MHz}$ for ${ }^{13} \mathrm{C}$. The ${ }^{1} \mathrm{H}$ and ${ }^{13} \mathrm{C}$ NMR spectra of AgEnCinn were recorded on a Bruker Avance $400 \mathrm{MHz}$ spectrophotometer, operating at $400.1 \mathrm{MHz}$ for ${ }^{1} \mathrm{H}$ and at $100.6 \mathrm{MHz}$ for ${ }^{13} \mathrm{C}$, while the ${ }^{1} \mathrm{H}$ and ${ }^{13} \mathrm{C}$ NMR spectra of ZnEnCinn were recorded on a Bruker Avance $600 \mathrm{MHz}$ spectrophotometer, operating at 600.1 $\mathrm{MHz}$ for ${ }^{1} \mathrm{H}$ and at $150.9 \mathrm{MHz}$ for ${ }^{13} \mathrm{C}$; samples were prepared in deuterated dimethyl sulfoxide (DMSO). An additional study on the stability of the $\mathrm{Ag}(\mathrm{I})$ complex in DMSO by ${ }^{1} \mathrm{H}$ NMR spectroscopy was performed. In this case, a sample of the compound was prepared and immediately analyzed (time zero). Successive measurements of this sample were performed after 1, 2, 3, 6 and $24 \mathrm{~h}$. The experiment was carried out in a Bruker Avance 400 $\mathrm{MHz}$ operating at $400.1 \mathrm{MHz}$ for ${ }^{1} \mathrm{H}$. Electrospray ionization quadrupole time-of-flight mass spectrometric measurements (ESIQTOF-MS) were carried out in a Waters Xevo instrument. A sample of AgEnCinn complex was solubilized in methanol $(0.1 \%$ formic acid $\mathrm{v} / \mathrm{v}$ ) at a concentration of $1 \mathrm{mg} / \mathrm{mL}$, and then further diluted 100 -fold in the same solvent mixture and immediately analyzed. Resulting solutions were directly infused into the instrument ESI source at a flow rate of $30 \mu \mathrm{L} \mathrm{min}{ }^{-1}$. Typical acquisition conditions were capillary voltage $3 \mathrm{kV}$, sampling cone voltage $30 \mathrm{~V}$ and source temperature of $120^{\circ} \mathrm{C}$. Thermogravimetric and differential thermal analyses (TGA/DTA) were performed on a Simultaneous TGA/DTA SEIKO EXSTAR 6000 thermoanalyzer, using the following conditions: synthetic air, flow rate of $100 \mathrm{~cm}^{3} \mathrm{~min}^{-1}$ and heating rate of $5{ }^{\circ} \mathrm{C} \min ^{-1}$ from $25^{\circ} \mathrm{C}$ to $900{ }^{\circ} \mathrm{C}$.

\subsection{Synthesis of EnCinn and its $A g(I)$ and $Z n(I I)$ complexes}

$N, N^{\prime}$-bis(trans-cinnamaldehyde)ethane-1,2-diamine (EnCinn) was prepared following literature procedures [10]. Catena- $\{(\mu-$ nitro- $\kappa_{-}^{2} 0,0$-) $\mu$-bis(trans-cinnamaldehyde)ethane-1,2-diamine- $\kappa^{2}$ $\left.N, N^{\prime}\right]$ silver(I)\} complex, hereafter represented as AgEnCinn, was obtained by adding $1.0 \mathrm{mmol}(0.1700 \mathrm{~g})$ of $\mathrm{AgNO}_{3}$ dissolved in $10 \mathrm{~mL}$ of acetonitrile to $1.0 \mathrm{mmol}(0.288 \mathrm{~g})$ of EnCinn also dissolved in $30 \mathrm{~mL}$ of acetonitrile. The reaction was kept under moderate heating $\left(50{ }^{\circ} \mathrm{C}\right)$ for $1 \mathrm{~h}$. A white polycrystalline solid was formed and collected by filtration, washed with acetonitrile and dried in a desiccator under silica. Following a similar procedure, $\left\{\left[N, N^{\prime}\right.\right.$-bis(trans-cinnamaldehyde)ethane-1,2-diamine) $-\kappa^{2} N$, $N^{\prime}$ ]dichloridezinc(II)\} complex, labeled as ZnEnCinn, was obtained. However, $1.0 \mathrm{mmol}(0.136 \mathrm{~g})$ of $\mathrm{ZnCl}_{2}$ was used instead of $\mathrm{AgNO}_{3}$. The yellow polycrystalline solid formed was also collected by filtration and dried in desiccator under silica. Both filtered solutions were left to stand protected from light at room temperature for few weeks, but no single crystals suitable for X-ray diffraction study were obtained. Thus, powder diffraction methods to retrieve their crystal and molecular structures (vide infra) were employed. Elemental analyses and ancillary analytical data for free EnCinn and for its $\mathrm{Ag}(\mathrm{I})$ and $\mathrm{Zn}(\mathrm{II})$ complexes are shown in Table 1.

\subsection{X-ray powder diffraction data collection and structure determination}

Crystal structures of the $\mathrm{Ag}(\mathrm{I})$ and $\mathrm{Zn}(\mathrm{II})$ complexes were obtained by state-of-the-art powder diffraction data measured on conventional laboratory equipment. To perform the powder diffraction analyses, polycrystalline samples of AgEnCinn and ZnEnCinn were gently grounded in an agate mortar and each powder was deposited in hollow of thin glass sample-holder plate, with nearly zero-background. The diffraction data were collected by overnight scans in the $2 \theta$ range of $3.7-105^{\circ}$ for AgEnCinn and 6$105^{\circ}$ for ZnEnCinn with steps of $0.02^{\circ}$ using a Bruker AXS D8 da Vinci diffractometer, equipped with $\mathrm{Ni}$-filtered and $\mathrm{Cu} \mathrm{K} \alpha$ radiation ( $\lambda=1.5418 \AA$ ), a Lynxeye linear position-sensitive detector and the following optics: primary beam Soller slits $\left(2.94^{\circ}\right)$, fixed divergence slit $\left(0.3^{\circ}\right)$ and receiving slit (7.68 and $8.92 \mathrm{~mm}$, for silver and zinc complexes, respectively). The generator was set at $40 \mathrm{kV}$ and 40 $\mathrm{mA}$. Approximate unit cell parameters were determined using 20 first standard peaks, followed by indexing through the single-value decomposition approach [11] implemented in TOPAS [12]. The space groups $C 2 / c$ and $P 2_{1} / c$ were chosen for AgEnCinn and ZnEnCinn, respectively, after careful systematic absence analysis and both cell parameters were refined using 3.7(6)-55 2th range by Pawley method [13]. In both cases, no higher symmetric system was suggested by PLATON [14]. The structure solution process for both cases was performed by the simulated annealing technique [15] also implemented in TOPAS. In addition, the EnCinn rigid body model based on single-crystal data [16] was built using Z-matrix formalism, with free rotations and translations as well torsion angles as described in Chart 1. It is worth note that there is no free rotation for $\mathrm{N} 1=\mathrm{C} 2$ and $\mathrm{C} 3=\mathrm{C} 4$ axes due the double bonds between these atoms.

Torsion angles, rotation and translation parameters of the ligand were used in simulated annealing step for both structures. In the specific case of AgEnCinn complex, translation and rotation values for nitrate ion (built also as Z-matrix) were left free as well translational parameters of $\mathrm{Ag}(\mathrm{I})$ ions. In the case of ZnEnCinn, a second rigid body $-\mathrm{ZnCl}_{2}$ was idealized with free rotation and

Table 1

Analytical and complementary data for EnCinn ligand and its complexes.

\begin{tabular}{|c|c|c|c|c|c|c|}
\hline \multirow[t]{2}{*}{ Compound } & \multirow[t]{2}{*}{ Formula (MW, $\mathrm{g} \mathrm{mol}^{-1}$ ) } & \multirow[t]{2}{*}{ Yield (\%) } & \multirow[t]{2}{*}{$\mathrm{MP}\left({ }^{\circ} \mathrm{C}\right)$} & \multicolumn{3}{|c|}{ Analytical data (\%) } \\
\hline & & & & $\mathrm{C}$ & $\mathrm{H}$ & $\mathrm{N}$ \\
\hline \multirow[t]{2}{*}{ EnCinn } & $\mathrm{C}_{20} \mathrm{H}_{20} \mathrm{~N}_{2}[288.0]$ & 90 & 108 & $(83.0)$ & $(6.84)$ & $(9.60)$ \\
\hline & & & & [83.3] & [6.99] & [9.71] \\
\hline \multirow[t]{2}{*}{ AgEnCinn } & $\mathrm{C}_{20} \mathrm{H}_{20} \mathrm{~N}_{3} \mathrm{O}_{3} \mathrm{Ag}$ [457.9] & 70 & $\operatorname{dec}^{*}$ & $(52.4)$ & $(4.55)$ & (9.09) \\
\hline & & & & {$[52.4]$} & [4.40] & [9.17] \\
\hline \multirow[t]{2}{*}{ ZnEnCinn } & $\mathrm{C}_{20} \mathrm{H}_{20} \mathrm{Cl}_{2} \mathrm{~N}_{2} \mathrm{Zn} \mathrm{[424.4]}$ & 87 & $\operatorname{dec}^{*}$ & (56.9) & $(4.81)$ & $(6.57)$ \\
\hline & & & & [56.6] & [4.74] & [6.60] \\
\hline
\end{tabular}

" Decompose over $300{ }^{\circ} \mathrm{C}$. Experimental data were provided in parentheses while calculated ones are in brackets. 


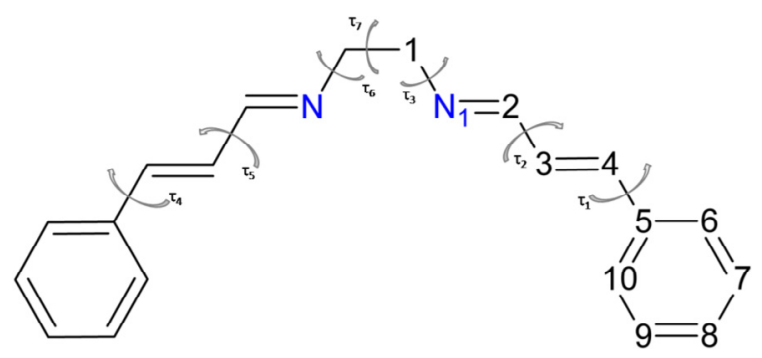

Chart 1. Sketch of EnCinn in E-isomer form where the torsion angles used in the simulated annealing and Rietveld refinement steps are described $\tau_{1}$ to $\tau_{7}$. Some of the carbon atoms were replaced by numbers and hydrogen atoms were omitted for a better visualization.

translation variables. However, $\mathrm{Cl}-\mathrm{Zn}-\mathrm{Cl}$ angle and $\mathrm{Cl}-\mathrm{Zn}$ distance bonds were left free with soft constrains (angle within 100-120 degree and distance bonds 2.1-2.4 $\AA$ ). In the refinement stage on AgEnCinn data, carried out by the Rietveld method [17], 38 parameters were refined including 6 parameters for background modeled by a Chebyshev polynomial function and a broad peak at $12.3^{\circ}$ (2th) was inserted to describe the presence of a small amorphous portion. The rigid body description introduced at the solution stage was maintained in the final refinement. An isotropic thermal parameter set up at $3.0(0.2) \AA^{2}$ was assigned to all atoms. For the ZnEnCinn case 39 parameters were refined, also using Rietveld method and, as usual, the 6 background parameters were modeled by a Chebyshev polynomial function.

\subsection{Anti-M. tuberculosis activity assay}

The anti-M. tuberculosis (anti-TB) activities of the compounds were determined by the Resazurin Microtiter Assay (REMA) method, as described in the literature [18]. Stock solutions of the tested compounds were prepared in DMSO at $10 \mathrm{~g} \mathrm{~L}^{-1}$ and diluted in Middlebrook 7H9 broth (Difco) supplemented with oleic acid, albumin, dextrose and catalase (OADC), performed by Precision XS (Biotek ${ }^{\circledR}$ ) to obtain the final drug concentration range of 0.09$25 \mu \mathrm{g} \mathrm{mL}^{-1}$. Rifampicin was dissolved in dimethyl sufoxide and used as standard drugs. A suspension of the M. tuberculosis $\mathrm{H}_{37} \mathrm{Rv}$ ATCC 27294 was cultured in Middlebrook 7H9 broth supplemented with OADC and 0.05\% Tween 80 . When the culture obtained a turbidity of McFarland standard No. 1, it was adjusted CFU by $5 \times 10^{5}$ CFU per $\mathrm{mL}$ and $100 \mu \mathrm{L}$ of the inoculum were added to each well of a 96-well microplate together with $100 \mu \mathrm{L}$ of the compounds. Samples were set up in three independent assays. The plates were incubated for 7 days at $37^{\circ} \mathrm{C}$. Resazurin (solubilized in water) was added ( $30 \mu \mathrm{L}$ of $0.01 \%)$. The fluorescence of the wells was measured after $24 \mathrm{~h}$ with a Cytation 3 (Biotek $\left.{ }^{\circledR}\right)$. The Minimum Inhibitory Concentration (MIC) was defined as the lowest concentration resulting in 90\% inhibition of growth of $M$. tuberculosis.

\section{Results and discussion}

\subsection{Elemental analyses}

Elemental analyses and complementary analytical data for EnCinn and its $\mathrm{Zn}(\mathrm{II})$ and $\mathrm{Ag}(\mathrm{I})$ complexes are shown in Table 1.

\subsection{Spectroscopic studies}

The infrared (IR) spectrum of EnCinn shows the characteristic bands of Schiff base compounds. The aromatic and aliphatic $v$ $(\mathrm{CH})$ stretchings are centered at 3070, 2924 and $2995 \mathrm{~cm}^{-1}$, respectively. The $v(\mathrm{C}=\mathrm{N})$ stretching frequency is observed at $1633 \mathrm{~cm}^{-1}$, while bands at 1489 and $1448 \mathrm{~cm}^{-1}$ are assigned to $v$ $(C=C)$ frequencies [19].

The AgEnCinn and ZnEnCinn IR spectra are quite similar each other and they are also related to the IR spectrum of EnCinn. The spectra of compounds are supplied as Supplementary material $\mathrm{S} 1$. The $v(\mathrm{C}=\mathrm{N})$ was observed at $1633 \mathrm{~cm}^{-1}$ for the EnCinn ligand. The same vibrational mode is observed at $1630 \mathrm{~cm}^{-1}$ and 1636 $\mathrm{cm}^{-1}$ for the $\mathrm{Ag}(\mathrm{I})$ and $\mathrm{Zn}(\mathrm{II})$ complexes, respectively. It is worthy to note that, in similar structures, minor down/up shift in the $v$ $(\mathrm{C}=\mathrm{N})$ band denotes the polymeric nature when ligand act as bridge, or 5 membered heterocycle rings when the ligand acts as a chelate [6]. In addition, for AgEnCinn, the strong band at 1384 $\mathrm{cm}^{-1}$ can be assigned to $v(\mathrm{NO})$ of the $\mathrm{NO}_{3}^{-}$group [6].

It was not possible to identify the $\mathrm{M}-\mathrm{L}$ bands such as $v(\mathrm{ZnCl}), v$ $(\mathrm{ZnN}), v(\mathrm{AgN})$ and $v(\mathrm{AgO})$ since these bands fall at lower frequency than $400 \mathrm{~cm}^{-1}$ and they are overlapped from organic moiety frequencies.

The ${ }^{1} \mathrm{H}$ and ${ }^{13} \mathrm{C}$ NMR spectra of EnCinn and its $\mathrm{Ag}(\mathrm{I})$ and $\mathrm{Zn}(\mathrm{II})$ complexes show slight changes in the chemical displacement of the atoms near the coordination environment, thus confirming the formation of complexes as pointed out in Table 2 .

To evaluate the stability of AgEnCinn complex in DMSO, additional ${ }^{1} \mathrm{H}$ NMR spectroscopic measurements with time were carried out. The compound has shown to be stable over $24 \mathrm{~h}$. The NMR spectra obtained with time are presented as Supplementary material S2.

\subsection{Mass spectrometric measurements}

ESI(+)-QTOF-MS analysis of AgEnCinn (see Supplementary material S3) indicates the presence of $\left[\mathrm{C}_{40} \mathrm{H}_{40} \mathrm{~N}_{4} \mathrm{Ag}\right]^{+}$ions $(\mathrm{m} / \mathrm{z}$ $685.220, \mathrm{C}_{40} \mathrm{H}_{40} \mathrm{~N}_{4} \mathrm{Ag}^{+}$) as the most abundant species, confirming the proposed composition for $\mathrm{Ag}(\mathrm{I})$ complex. The $\left[\mathrm{C}_{20} \mathrm{H}_{20} \mathrm{~N}_{2} \mathrm{Ag}\right]^{+}$ ions were also observed with similar composition except for an additional loss of ligand ( $\left.\mathrm{m} / \mathrm{z} 395.0587, \mathrm{C}_{20} \mathrm{H}_{20} \mathrm{~N}_{2} \mathrm{Ag}^{+}\right)$. The experimental isotopic pattern for the most abundant $\left[\mathrm{C}_{40} \mathrm{H}_{40} \mathrm{~N}_{4} \mathrm{Ag}\right]^{+}$ion is in good agreement with the respective theoretical prediction (Fig. S2b). The mass error for this ion was $-11.85 \mathrm{ppm}\left(\mathrm{C}_{40} \mathrm{H}_{40} \mathrm{~N}_{4^{-}}\right.$ $\mathrm{Ag}^{+}$, calcd. $m / z$ 683.2304, exp. $m / z$ 683.2173), considering the monoisotopic ion of the composition.

\subsection{Thermal analysis}

The thermogravimetric data confirmed the composition of the AgEnCinn complex formulated as $\mathrm{C}_{20} \mathrm{H}_{20} \mathrm{AgN}_{3} \mathrm{O}_{3}$. Oxidation of the

Table 2

Solution-state ${ }^{1} \mathrm{H}$ and ${ }^{13} \mathrm{C}\left\{{ }^{1} \mathrm{H}\right\}$ NMR data for EnCinn ligand and its complexes.

\begin{tabular}{llll}
\hline \multirow{2}{*}{ Carbon } & \multicolumn{2}{l}{ Chemical Shifts $(\mathrm{ppm})$} & \\
\cline { 2 - 4 } & EnCinn & AgEnCinn & ZnEnCinn \\
\hline C1 & 61.3 & 61.6 & 58.9 \\
C2 & 163.4 & 168.3 & 166.8 \\
C3 & 127.2 & 127.4 & 126.2 \\
C4 & 135.5 & 134.6 & 134.9 \\
C5 & 141.3 & 145.5 & 144.9 \\
C6, C10 & 128.8 & 128.8 & 129.0 \\
C7,C9 & 129.1 & 130.0 & 129.9 \\
C8 & 128.0 & 127.6 & 127.5 \\
Hydrogen & & & \\
H-C1 & $3.71 \mathrm{~s}, 2 \mathrm{H}$ & $4.00 \mathrm{~s}, 2 \mathrm{H}$ & $3.81 \mathrm{~s}, 2 \mathrm{H}$ \\
H-C2 & $8.06 \mathrm{~d}, 1 \mathrm{H}$ & $8.44 \mathrm{~d}, 1 \mathrm{H}$ & $8.32 \mathrm{~d}, 1 \mathrm{H}$ \\
H-C3 & $6.91 \mathrm{~m}, 1 \mathrm{H}$ & $7.08 \mathrm{~m}, 1 \mathrm{H}$ & $7.07 \mathrm{~m}, 1 \mathrm{H}$ \\
H-C4 & $7.09 \mathrm{dd}, 1 \mathrm{H}$ & $7.26 \mathrm{dd}, 1 \mathrm{H}$ & $7.35 \mathrm{dd}, 1 \mathrm{H}$ \\
H-C6, H-C10 & $7.57 \mathrm{dd}, 2 \mathrm{H}$ & $7.47 \mathrm{~m}, 2 \mathrm{H}$ & $7.60 \mathrm{~m}, 2 \mathrm{H}$ \\
H-C7, H-C9 e H-C8 & $7.33 \mathrm{~m}, 3 \mathrm{H}$ & $7.34 \mathrm{~m}, 3 \mathrm{H}$ & $7.48 \mathrm{~m}, 3 \mathrm{H}$ \\
\hline
\end{tabular}

The carbon codes follow the labeling proposed in Chart 1. 
ligand starts at $177^{\circ} \mathrm{C}$ and continues until $543^{\circ} \mathrm{C}$, showing a mass loss of $77.2 \%$. The residue of thermal decomposition matches with $\mathrm{Ag}^{\circ}$ (Calcd. 23.5\%. Found 22.8\%). In the DTA curve we can see exothermic peaks at $187{ }^{\circ} \mathrm{C}, 209^{\circ} \mathrm{C}, 408^{\circ} \mathrm{C}$ and $462{ }^{\circ} \mathrm{C}$ related to ligand oxidation. The TGA/DTA curves are presented as Supplementary material - S4.

\subsection{Crystal structure studies}

The crystal structures of the AgEnCinn and ZnEnCinn complexes were determined and refined by state-of-art powder diffraction data. As described in our papers previously published [20,21], the extensive uses of rigid body and over than 20 parameters in the simulated annealing stage does not allow a deep discussion of intramolecular features. Nevertheless, the analysis of the powder diffraction data combined with the spectroscopic and analytical results provided us robust crystal models. Indeed, important crystallochemical information such as stoichiometry, molecular con-

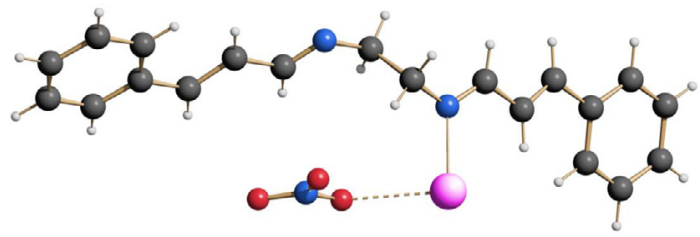

Fig. 1. The asymmetric unit of AgEnCinn complex. The silver(I) ion is colored in pink while carbon, hydrogen, nitrogen and oxygen atoms were colored as black, white, blue and red, respectively. (Color online.)

Table 3

Main crystallographic data of AgEnCinn and ZnEnCinn complexes.

\begin{tabular}{lll}
\hline & AgEnCinn & ZnEnCinn \\
\hline Empirical formula & $\mathrm{C}_{20} \mathrm{H}_{20} \mathrm{AgN}_{3} \mathrm{O}_{3}$ & $\mathrm{C}_{20} \mathrm{H}_{20} \mathrm{~N}_{2} \mathrm{Cl}_{2} \mathrm{Zn}$ \\
Formula weight & 457.87 & 424.29 \\
$T(\mathrm{~K})$ & 298 & \\
$\lambda(\mathrm{Cu} \mathrm{K \alpha})(\AA)$ & 1.5418 & \\
Crystal system & monoclinic & \\
Space group & $C 2 / c$ & $P 2{ }_{1} / c$ \\
$a(\AA)$ & $40.850(1)$ & $7.196(3)$ \\
$b(\AA)$ & $11.636(3)$ & $20.341(8)$ \\
$c(\AA)$ & $8.554(2)$ & $14.004(4)$ \\
$\beta\left({ }^{\circ}\right)$ & $103.478(3)$ & $94.961(2)$ \\
$V\left(\AA^{3}\right)$ & $3954.0(2)$ & $2042.1(1)$ \\
$Z$ & 8 & 4 \\
$\mathrm{D}_{\text {calc }}\left(\mathrm{g} \mathrm{cm}^{-3}\right)$ & 1.540 & 1.381 \\
$\mu\left(\mathrm{mm}^{-1}\right)$ & 8.44 & 4.11 \\
$F(000)$ & 1856 & 872 \\
Number of parameters & 38 & 39 \\
$R_{\text {Bragg, }} R_{w p}, G O F$ & $0.024,0.09,8.3$ & $0.057,0.098,10.9$ \\
\hline
\end{tabular}

Table 4

Selected distance and angle bonds and interactions of EnCinn complexes.

\begin{tabular}{lllll}
\hline Complexes & Distance $(\AA)$ & & Angle $\left.{ }^{\circ}\right)$ \\
\hline \multirow{2}{*}{ AgEnCinn } & $\mathrm{Ag}-\mathrm{N}$ & $2.399(2)$ & $\mathrm{N}-\mathrm{Ag}-\mathrm{N}^{\prime}$ & $166.12(1)$ \\
& $\mathrm{Ag}-\mathrm{N}^{\prime}$ & $2.298(3)$ & $\mathrm{N}-\mathrm{Ag}-\mathrm{O}$ & $98.13(2)$ \\
& $\mathrm{Ag}-\mathrm{O}$ & $2.330(2)$ & $\mathrm{Ag}-\mathrm{O}--\mathrm{Ag}^{\prime \prime}$ & $110.17(5)$ \\
& $\mathrm{Ag}^{\prime \prime}-\mathrm{O}$ & $2.956(2)$ & $\mathrm{N}^{\prime}-\mathrm{Ag}-\mathrm{O}$ & $96.40(3)$ \\
& & & $\mathrm{N}-\mathrm{Zn}-\mathrm{N}$ & $79.86(4)$ \\
ZnEnCinn & & & $\mathrm{Cl}-\mathrm{Zn}-\mathrm{Cl}$ & $113.61(5)$ \\
& $\mathrm{N} 1-\mathrm{Zn}$ & $2.171(1)$ & $\mathrm{Cl} 1-\mathrm{Zn}-\mathrm{N} 1$ & $113.93(5)$ \\
& $\mathrm{N} 21-\mathrm{Zn}$ & $2.228(1)$ & $\mathrm{Cl} 1-\mathrm{Zn}-\mathrm{N} 21$ & $111.10(5)$ \\
& $\mathrm{Cl} 1-\mathrm{Zn}$ & $2.142(9)$ & $\mathrm{Cl} 2-\mathrm{Zn}-\mathrm{N} 11$ & $115.76(6)$ \\
& $\mathrm{Cl} 2-\mathrm{Zn}$ & $2.126(9)$ & $\mathrm{Cl} 2-\mathrm{Zn}-\mathrm{N} 21$ & $118.45(7)$ \\
\hline
\end{tabular}

Symmetry codes: $\mathrm{i}=0.5-x, 0.5+y, 0.5-z$; ii $=0.5-x, 1.5-y, 1-z$. (-) bond and $(--)$ interaction. formation and connectivity, and overall crystal packing features could be afforded in both cases.

The sketch of the crystal model for silver complex is shown in Fig. 1 while the final Rietveld refinement plot is provided as Supplementary material S5. Table 3 contains the relevant crystal data for the silver and zinc complexes, while Table 4 contains selected bond distances and angles as well important interactions for the complexes.

In the AgEnCinn complex the bidentate ligand bridges between two $\mathrm{Ag}(\mathrm{I})$ centers avoiding chelation toward a single silver(I) ion like in similar silver complexes [6]. As expected, the Ag-N bridge induces the formation of an inorganic 1D polymer, growing up parallel to the $b$ axis (see Fig. 2), where $\mathrm{Ag}-\mathrm{N}$ and $\mathrm{Ag}-\mathrm{N}^{\prime}$, bond distances are $2.399 \AA$ and $2.298 \AA$, respectively. In addition, the nitrate group is also bonded to $\mathrm{Ag}(\mathrm{I})$ ions by only one oxygen atom at $2.30 \AA$ A. Furthermore, the same oxygen atom bonded to $\mathrm{Ag}(\mathrm{I})$ has a strong interaction with another $\mathrm{Ag}(\mathrm{I})$, by means of $2.957 \AA$. Since each $\operatorname{Ag}(\mathrm{I})$ is coordinated by two distinct ligands by their iminic

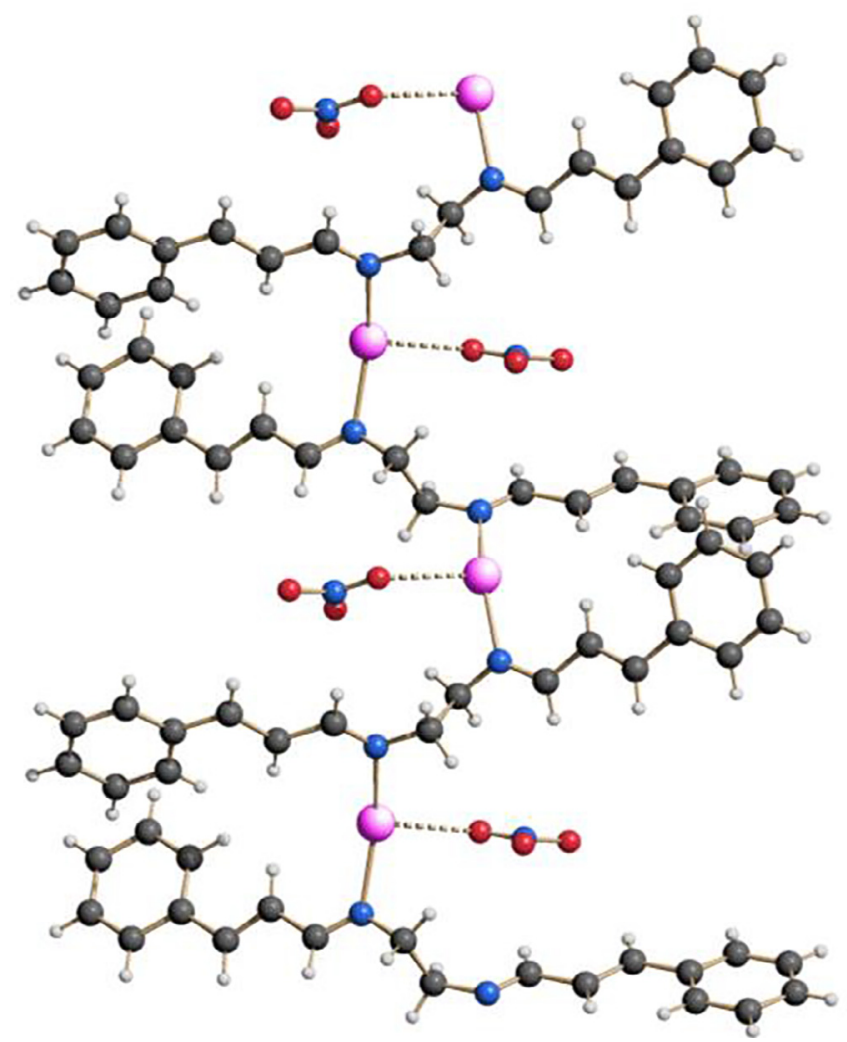

Fig. 2. The 1D polymer of AgEnCinn parallel to $b$ axis. All atoms were colored following code of Fig. 1. (Color online.)

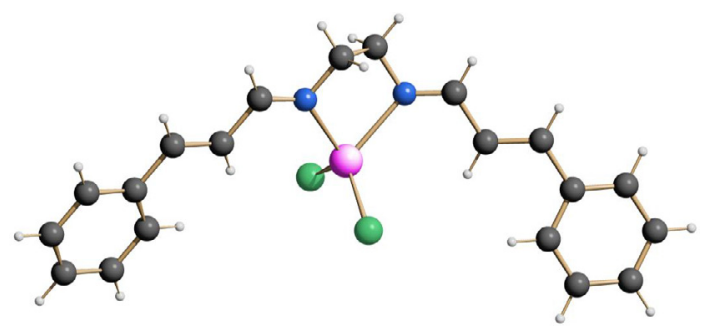

Fig. 3. The crystal structure model of ZnEnCinn. The pink sphere represents zinc(II), where it is surrounded by two chlorine ions (colored in green) and two nitrogen atoms (blue ones). The carbon and hydrogen atoms were represented in black and white colors, respectively. (Color online.) 


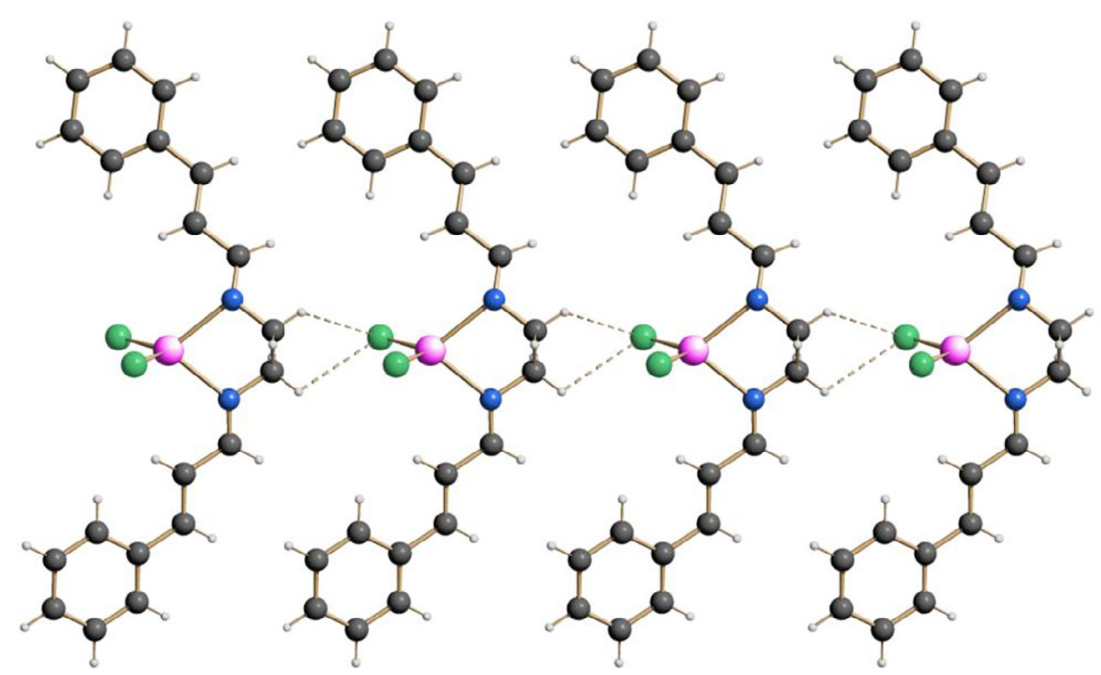

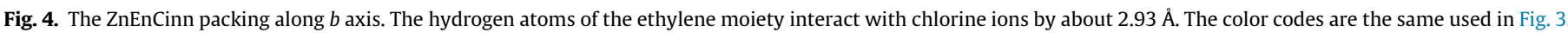
(Color online.)

Table 5

Biological results - anti-TB values for the free ligand, $\mathrm{Ag}(\mathrm{I})$ and $\mathrm{Zn}(\mathrm{II})$ complexes, SSD and the metal salts.

\begin{tabular}{llll}
\hline Compound & MW $\left(\mathrm{g} \mathrm{mol}^{-1}\right)$ & w\%, Metal & MIC $\left(\mathrm{mg} \mathrm{L}^{-1}\right)\left[\mu \mathrm{mol} \mathrm{L}^{-1}\right]$ \\
\hline EnCinn & 260 & - & $>25$ \\
AgEnCinn & 457.9 & 23.5 & $10.4[22.7]$ \\
ZnEnCinn & 424.3 & 15.4 & $>25$ \\
SSD & 357 & 30.2 & $7.80[21.8]$ \\
Rifampicin & 822.9 & - & $0.025[0.03]$ \\
$\mathrm{AgNO}_{3}$ & 169.9 & 63.5 & $12.5[73.6]$ \\
$\mathrm{ZnCl}_{2}$ & 136 & 48.0 & $>25$ \\
\hline
\end{tabular}

nitrogen atoms and by only one oxygen atom from the nitrate ion, and considering the bond distances and angles described in the Table 4, the $\operatorname{Ag}(\mathrm{I})$ coordination geometry can be described as a T-shaped geometry.

The crystal model for ZnEnCinn is shown in Fig. 3 and the final Rietveld refinement plot is provided as Supplementary material S6. The ZnEnCinn complex has a single molecular structure and the packing is generated by $\mathrm{Cl} \cdots \mathrm{H}-\mathrm{C}$ weak interactions as shown in Fig. 4. The $\mathrm{Zn}$ (II) ion has the common pseudo-tetrahedral geometry, defined by two chlorides and one ligand, acting as chelating, as shown in Fig. 3 [22]. Indeed, the ethylenediamine moiety of the ligand makes a five-membered ring with angle $\mathrm{N}-\mathrm{Zn}-\mathrm{N}$ lower than $80^{\circ}$, as described in the Table 5.

\subsection{Antituberculosis assay}

Biological studies concerning the anti M. tuberculosis activity of EnCinn and the $\mathrm{Ag}(\mathrm{I})$ and $\mathrm{Zn}(\mathrm{II})$ complexes are shown in Table 5. In addition, the standard drug silver sulfadiazine (SSD) and the precursor salts $\mathrm{AgNO}_{3}$ and $\mathrm{ZnCl}_{2}$ were also evaluated against $M$. tuberculosis in the same experimental conditions. The values obtained are shown in Table 5.

As recently published [6], pure $\mathrm{AgNO}_{3}$ solution is very toxic for M. tuberculosis as well for VERO cells suggesting that free silver ions should be avoided in biological systems. On the other hand, as described in Table 5, pure EnCinn does not possess biological activity against $M$. tuberculosis, indicating that the complexation of silver(I) with non-toxic organic molecules can afford new drugs with activity against TB. Hence, the AgEnCinn complex reported in this work show activity against $M$. tuberculosis with MIC value of $22.7 \mu \mathrm{mol} \mathrm{L}^{-1}$ nearly to SSD reference $\left(21.8 \mu \mathrm{mol} \mathrm{L}^{-1}\right)$. The ZnEnCinn complex showed no inhibitory activity against $M$. tuberculosis in the same experimental conditions.

\section{Conclusion}

Silver(I) and zinc(II) complexes with EnCinn were synthesized and presented molar compositions 1:1 metal/ligand. Chemical analyses confirmed the minimal formulas $\mathrm{C}_{20} \mathrm{H}_{20} \mathrm{~N}_{2} \mathrm{AgNO}_{3}$ and $\mathrm{C}_{20} \mathrm{H}_{20} \mathrm{~N}_{2} \mathrm{Cl}_{2} \mathrm{Zn}$ for the AgEnCinn and ZnEnCinn, respectively. Crystallographic studies were carried out using powder diffraction state-of-art technique. The AgEnCinn complex has a polymeric structure where EnCinn bridges between $\operatorname{Ag}(\mathrm{I})$ parallel to $b$ axis. In the ZnEnCinn complex the ligand acts as a chelating agent and two independent chlorine ions complete the tetrahedral coordination around the $\mathrm{Zn}(\mathrm{II})$ center. The AgEnCinn showed good and promising biological activity against $M$. tuberculosis, showing MIC value of $10.4 \mathrm{mg} \mathrm{L}^{-1}$ or $22.7 \mu \mathrm{mol} \mathrm{L}^{-1}$.

\section{Acknowledgments}

This study was supported by grants from the Brazilian Agencies FAPESP (São Paulo State Research Council, Grant \# 2015/25114-4 CNPq (National Council of Scientific and Technological Development, Grant \# 442123/2014-0) and Rede Mineira de Química (RQ-MG) supported by FAPEMIG (Project: REDE-113/10; Project: CEX - RED-00010-14).

\section{Appendix A. Supplementary data}

CCDC 1538347 and 1538348 contains the supplementary crystallographic data. These data can be obtained free of charge via http://www.ccdc.cam.ac.uk/conts/retrieving.html, or from the Cambridge Crystallographic Data Centre, 12 Union Road, Cambridge CB2 1EZ, UK; fax: (+44) 1223-336-033; or e-mail: deposit@ccdc.cam.ac.uk. IR, ${ }^{1} \mathrm{H}$ NMR and mass spectra, along with Rietveld plots and TG/DTA curves for complexes and ligands, are available as supplementary materials. Supplementary data associated with this article can be found, in the online version, at https://doi.org/10.1016/j.poly.2018.02.024. 


\section{References}

[1] Global Tuberculosis Report 2017. Geneva: World Health Organization 2017. ISBN 978-92-4-156551-6.

[2] A. Cuin, A.C. Massabni, C.Q.F. Leite, D.N. Sato, A. Neves, B. Szpoganicz, M.S. Silva, A.J. Bortoluzzi, Synthesis, X-ray structure and antimycobacterial Activity of Silver complexes with alfa-hydroxycarboxylic acids, J. Inorg. Biochem. 101 (2007) 291.

[3] G.A. Pereira, A.C. Massabni, E.E. Castellano, L.A. Sodré Costa, C.Q.F. Leite, F.R. Pavan, A. Cuin, A broad study of two new promising antimycobacterial drugs: $\mathrm{Ag}(\mathrm{I})$ and $\mathrm{Au}(\mathrm{I})$ complexes with 2-(2-thienyl)benzothiazole, Polyhedron 38 (2012) 291.

[4] G.S.M. Costa, P.P. Corbi, C. Abbehausen, A.L.B. Formiga, W.R. Lustri, A. Cuin, Silver(I) and gold(I) complexes with penicillamine: Synthesis, spectroscopic characterization and biological studies, Polyhedron 34 (2012) 210.

[5] A. Cuin, A.C. Massabni, G.A. Pereira, C.Q.F. Leite, F.R. Pavan, R. Sesti-Costa, T.A. Heinrich, C.M. Costa-Neto, 6-Mercaptopurine complexes with silver and gold ions: Anti-tuberculosis and anti-cancer activities, Biomed. Pharma. 65 (2011) 334.

[6] S.A. Silva, C.Q.F. Leite, F.R. Pavan, N. Masciocchi, A. Cuin, Coordinative versatility of a Schiff base containing thiophene: Synthesis, characterization and biological activity of zinc(II) and silver(I) complexes, Polyhedron 79 (2014) 170.

[7] I.L. Paiva, G.S.G. Carvalho, A.D. Silva, P.P. Corbi, F.R.G. Bergamini, A.L.B. Formiga, R. Diniz, W.R. Carmo, C.Q.F. Leite, F.R. Pavan, A. Cuin, Silver(I) complexes with symmetrical Schiff bases: Synthesis, structural characterization, DFT studies and antimycobacterial assays, Polyhedron 62 (2013) 104.

[8] M. Darawsheha, H.A. Alia, A.L. Abuhijleha, E. Rappocciolob, M. Akkawic, S. Jaberc, S. Maloula, Y. Husseinb, New mixed ligand zinc(II) complexes based on the antiepileptic drug sodium valproate and bioactive nitrogen-donor ligands. Synthesis, structure and biological properties, Eur. J. Med. Chem. 82 (2014) 152.

[9] H. Wang, H. Yuan, S. Li, Z. Li, M. Jiang, Synthesis, antimicrobial activity of Schiff base compounds of cinnamaldehyde and amino acids, Bioorg. Med. Chem. Lett. 26 (2016) 809.
[10] K. Karupaiyan, V.G. Puranik, A.R.A.S. Deshmukh, B.M. Bhawal, Stereoselective synthesis of cis-Bis- $\beta$-lactams linked with an ethylene bridge, Tetrahedron 56 (2000) 8555.

[11] A.A. Coelho, Indexing of powder diffraction patterns by iterative use of singular value decomposition, J. Appl. Crystallogr. 36 (2003) 86.

[12] TOPAS-R, General Profile and Structure Analysis Software for Powder Diffraction Data, Version 4.2, Karlsruhe, Germany, Bruker AXS, 2009.

[13] G.S. Pawley, Unit-cell refinement from powder diffraction scans, J. Appl, Crystallogr. 14 (1981) 357.

[14] A.L. Spek, Structure validation in chemical crystallography, Acta Crystallogr. D 65 (2009) 148.

[15] A. Coelho, Whole-profile structure solution from powder diffraction data using simulated annealing, J. Appl. Crystallogr. 22 (2000) 899.

[16] A.D. Khalaji, M. Weil, Crystal Structure of $N, N^{\prime}$-Bis(trans-cinnamaldehyde) ethylenediimine, Anal. Sci. 23 (2007) 187.

[17] R.A. Young, The Rietveld Method, IUCr Monograph N.5, Oxford University Press, New York, 1981.

[18] J.C. Palomino, A. Martin, M. Camacho, H. Guerra, J. Swings, F. Portaels, Resazurin microtiter assay plate: simple and inexpensive method for detection of drug resistance in Mycobacterium tuberculosis, Antimicrob. Agents Chemother. 46 (2002) 2720.

[19] V.Z. Mota, G.S.G. de Carvalho, P.P. Corbi, F.R.G. Bergamini, A.L.B. Formiga, R Diniz, M.C.R. Freitas, A.D. da Silva, A. Cuin, Crystal structure and theoretical studies of the keto-enol isomerism of $N$, N'-bis(salicylidene)-ophenylenediamine (salophen), Spectrochim. Acta, Part A: Mol. Biomol. Spectrosc. 99 (2012) 110.

[20] J.H.B. Nunes, R.E.F. de Paiva, A. Cuin, W.R. Lustri, P.P. Corbi, Silver complexes with sulfathiazole and sulfamethoxazole: Synthesis, spectroscopic characterization, crystal structure and antibacterial assays, Polyhedron 85 (2015) 437.

[21] L.F. Marques, A. Cuin, G.S.G. De Carvalho, M.V. Dos Santos, S.J.L. Ribeiro, F.C. Machado, Energy transfer process in highly photoluminescent binuclear hydrocinnamate of europium, terbium and gadolinium containing 1,10phenanthroline as ancillary ligand, Inorg. Chim. Acta 441 (2016) 67.

[22] S. Alvarez, D. Avnir, Continuous chirality measures of tetracoordinate bis (chelate) metal complexes, Dalton Trans. (2003) 562 